\title{
Pyrolytic Conversion of Olive Mill Wastewater Sludge to Biofuels Using Red Mud as Catalyst
}

\author{
Foster Aryi Agblevor ${ }^{1,}$, , Hamza Abdellaoui ${ }^{1}$, Kamel Halouani ${ }^{2}$, Sedat Hakis Beis ${ }^{1}$ \\ ${ }^{1}$ Department of Biological Engineering, Utah State University, Logan, USA \\ ${ }^{2}$ National Engineering School of Sfax, University of Sfax, Sfax, Tunisia
}

Email address:

foster.agblevor@usu.edu (F. A. Agblevor)

${ }^{*}$ Corresponding authors

\section{To cite this article:}

Foster Aryi Agblevor, Hamza Abdellaoui, Kamel Halouani, Sedat Hakis Beis. Pyrolytic Conversion of Olive Mill Wastewater Sludge to Biofuels Using Red Mud as Catalyst. International Journal of Energy and Power Engineering. Vol. 6, No. 6, 2017, pp. 108-120. doi: 10.11648/j.ijepe.20170606.14

Received: September 18, 2017; Accepted: October 28, 2017; Published: December 12, 2017

\begin{abstract}
Olive mill wastewater sludge (OMWS) is an environmental pollutant in olive oil industry. The problem stems from the strong odor and poor biodegradability of OMWS because of its high phenolic compounds. In most Mediterranean countries, olive mill wastewater is stored in evaporation ponds and the residual sludge is landfilled for disposal. To address this environmental pollution problem, fluidized bed catalytic pyrolysis of OMWS was developed to produce pyrolysis liquids that are stable, low viscosity (5-7 cP), neutral $\mathrm{pH}(6-7)$, and high higher heating value $(41 \mathrm{MJ} / \mathrm{kg})$. The pyrolysis was conducted at $400-500^{\circ} \mathrm{C}$ in a red mud catalyst bed. The yields of the organic fraction were $29-35$ mass $\%$; char/coke yield was $20-29$ mass $\%$; and gas yield was 24-37 mass $\%$. The ${ }^{13} \mathrm{C}$ NMR and GC/MS analyses of the liquid products showed predominance of aliphatic hydrocarbons and small fractions of aromatic hydrocarbons and ketones. The composition of these liquid products is in sharp contrast with most lignocellulosic biomass pyrolysis products which are normally rich in aromatic compounds and have very low aliphatic product content. In the absence of the red mud catalyst, the liquid product was viscous and contained acidic compounds.
\end{abstract}

Keywords: Catalytic Pyrolysis, Red Mud, Olive Mill Wastewater Sludge, Bubbling Fluidized Bed

\section{Introduction}

Olive oil production is a major industry in Mediterranean countries and it is also a growing industry in South Africa, Australia, and California in the USA. The production of olive oil, using either the traditional or the modern three-phase process generates large quantities of wastewater that is rich in phenolic compounds and therefore not easily biodegradable [1]. The olive mill wastewater contains pulp, mucilage, pectins, oil, and many other compounds that are suspended in a stable emulsion [2]. The most important disposal methods include storage ponds where most of the water is evaporated and the residual sludge (olive mill wastewater sludge (OMWS)) is then sent to landfills [3, 4]. The storage pond method needs large land areas, produces bad odor, causes soil infiltration, and insect infestation [2].

Olive mill wastewater (OMW) is also disposed by direct application to agricultural lands as fertilizer [5-7] because of its high potassium, phosphorous, and other micronutrient content. The land application however has some disadvantages because of the high salt content and its use has been cautioned by some researchers [5] The chemical compositional analysis of OMW showed large fractions of organic acids, lipids, alcohols, carbohydrates, polyphenolic compounds, and many others [3]. Thus, it is conceivable to apply pyrolysis technology to such feedstock to convert it to biofuels, which will simultaneously solve waste disposal problem and produce green energy.

Pyrolysis of lignocellulosic biomass has been extensively studied in the past to produce biofuels for transportation and other applications. Application of pyrolysis technology to waste products for fuel production has been less studied [812]. Agblevor et al., [9] studied the conversion of poultry litter into biofuels and found that the liquids had high viscosities and low yields but the energy content of the fuel 
was higher than that of wood pyrolysis oils. Pyrolysis studies have also been conducted on olive mill wastes especially the pomace, pits and stones [13-15]. These studies showed that char yields were high but the quality of the liquid fuels were similar to other biomass pyrolysis liquids. Pyrolysis of the OMWS has not been extensively reported and there is hardly any report on the catalytic pyrolysis OMWS both in patent and published literature.

Red mud or red sludge is the solid residue from the processing of bauxite to alumina using the Bayer process. Red mud is a complex mixture of metallic oxides such as ferric oxide, aluminum oxide, titanium dioxide, magnesium oxide, calcium oxide, silicon oxide, and other minor compounds, in addition to the residual sodium hydroxide used in the extraction process. Catalytic applications of red mud have been extensively reviewed by [16]. This material has been investigated by several researchers for catalytic applications such as hydrodechlorination [17], hydrogenation of anthracene [18, 19], pyrolysis of waste plastics and waste oils $[20,21]$, hydrogenation and liquefaction of rye straw [22], upgrading of hemp-seed pyrolysis oils [23], and acetic acid [24]. In most of these applications red mud was activated through acid treatment and other modifications. However, there has not been any systematic investigation of using red mud as fractional catalytic pyrolysis catalyst. The ultimate goal of these studies is to develop catalytic pyrolysis process for converting OMWS into higher value products. In this paper we report the investigation of red mud as a catalyst for conversion of OMWS into pyrolysis oils for fuel applications.

\section{Materials and Methods}

\subsection{Materials}

OMWS was collected from a Tunisian evaporation pond containing 1-2 years old material (Agareb 3030, Sfax, Tunisia). The OMWS was dried at room temperature to equilibrium moisture content and then ground in a Wiley mill (model 4) to pass a 2-mm screen. The ash content was determined according to ASTM E1755. The extractives content of the OMWS was determined sequentially using three solvents (hexanes, $95 \mathrm{vol} \%$ ethanol, and de-ionized water) in a Soxhlet extractor. About $15 \mathrm{~g}$ of ground OMWS was first extracted with $250 \mathrm{ml}$ of hexanes for $8 \mathrm{~h}$ and then followed with extraction with $95 \%$ ethanol for another $8 \mathrm{~h}$ and finally with de-ionized water for $8 \mathrm{~h}$. The extracts were recovered after evaporation in Buchi rotary evaporator under vacuum at $40 \mathrm{psi}$ and $40^{\circ} \mathrm{C}$.

The hexane extract (HE) was further analyzed for saponifiable and un-saponifiable material using ASTM D1962-67 (Reapproved 1973). Approximately, $4 \mathrm{~g}$ of the HE was transferred into an Erlenmeyer flask and $25 \mathrm{ml}$ of alcoholic $\mathrm{KOH}$ solution was added to the sample and to an empty Erlenmeyer flask (blank). A reflux condenser was attached to each and flask refluxed for one hour. After cooling both flasks to room temperature, phenolphthalein was added to both flasks and titration was conducted using $0.5 \mathrm{~N}$ of $\mathrm{H}_{2} \mathrm{SO}_{4}$ until reaching the equivalence point. The saponification value of the $\mathrm{HE}$ was calculated using the equation below:

$$
\text { Saponification value }=[(\mathrm{B}-\mathrm{A}) \times \mathrm{N} \times 56.1] / \mathrm{C}
$$

Where: $\mathrm{A}=$ volume of $\mathrm{H}_{2} \mathrm{SO}_{4}$ used to titrate the sample (mL); $\mathrm{B}=$ volume of $\mathrm{H}_{2} \mathrm{SO}_{4}$ used to titrate the blank (mL); $\mathrm{N}$ = normality of the $\mathrm{H}_{2} \mathrm{SO}_{4} ; \mathrm{C}=$ mass of sample used ( $\mathrm{g}$ ).

The acid value, percent free fatty acid (FFA), ester value, and percent glycerine were also determined for the HE fraction. The following formulae were used in calculating the various values:

$$
\begin{gathered}
\% \mathrm{FFA}=\text { Acid value } \times 0.503 ; \\
\text { Ester value }=(\text { saponification value })-(\text { acid value }) \\
\% \text { glycerine }=(\text { Ester value }) \times 0.0546[25]
\end{gathered}
$$

The higher heating value (HHV) of the OMWS was determined using IKA C2000 basic bomb calorimeter (IKA Works, Inc., Wilmington, NC). The elemental composition of the OMWS was determined using Thermo Scientific Flash 2000 organic elemental analyzer (Thermo Fisher Scientific, Cambridge, UK).

The red mud supplied by Sherwin Alumina Co LLC, (Gregory, TX), was dried at ambient laboratory conditions, ground with mortar and pestle and sieved to appropriate particle size $(125-180 \mu \mathrm{m})$ for fluidized bed pyrolysis studies. The composition of the red mud was determined by $\mathrm{x}$-ray diffraction (XRD) using X'Pert Pro XRD spectrometer (PAN analytic Inc, Westborough, MA) and X-ray florescence (XRF) using Phillips PW2404 XRF spectrometer (PAN analytic Inc, Westborough, MA). The Brunauer-Emmett-Teller (BET) method was used to measure the surface area of the red mud using Quantachrome BET surface analyzer (Quantachrome Instruments, Boyton Beach, FL).

\subsection{Pyrolysis of Olive Mill Wastewater Sludge (OMWS)}

The OMWS was very sticky even after drying in the fume hood and did not flow easily. To improve its flow properties, 20 mass\% silicon carbide was mixed with the ground OMWS for all the pyrolysis studies.

Fast pyrolysis experiments were carried out using a benchscale fluidized bed reactor located in the USTAR Bioenergy Center, Utah State University, Logan, UT. The details of the reactor have been published in Agblevor et al [9]. The pyrolysis unit comprised of a K-Tron volumetric feeder, a 50 $\mathrm{mm}$ in diameter and $500 \mathrm{~mm}$ in length bubbling fluidized bed reactor equipped with a $100 \mu \mathrm{m}$ porous metal gas distributer. The reactor was externally heated with a three-zone electric furnace (Thermcraft, Winston-Salem, NC) and was connected, in series, to a hot gas filter, two condensers cooled with ethylene glycol/water mixture, an electrostatic precipitator, and a coalescing filter. About $100 \mathrm{~g}$ of silica sand or red mud was used as the fluidizing medium. The red mud was calcined at $550^{\circ} \mathrm{C}$ for five hours before being used 
for the pyrolysis reactions. When using silica sand as the fluidizing medium, a total of $18.3 \mathrm{~L} / \mathrm{min}$ of nitrogen gas was used to fluidize the bed and entrain the feedstock into the reactor. For the red mud a total of $8 \mathrm{~L} / \mathrm{min}$ of nitrogen was used. Using a screw feeder, the feedstock was conveyed from the hopper to an entrainment zone where nitrogen gas was used $(5 \mathrm{~L} / \mathrm{min}$ for both catalytic and non-catalytic experiments) to entrain the feed through a jacketed air-cooled feeder tube into the fluidized bed. The biomass feed rate was $200 \mathrm{~g} / \mathrm{h}$. During pyrolysis, the mixture of vapours, gases, and some of the biochar that exited the reactor were separated by the hot gas filter maintained at $400^{\circ} \mathrm{C}$ to avoid the condensation of vapours going through it. The biochar-free vapours and non-condensable gases were then passed through two condensers connected in series and maintained at $-8^{\circ} \mathrm{C}$ using an 18 -liter Haake A82 Temperature Bath/Recirculator (Haake, Karlsruhe, Germany). The cooling liquid was a mixture of 50/50 ethylene glycol and water. The aerosols and non-condensable gases that exited the condensers were passed through an electrostatic precipitator (ESP) maintained at 20 kilovolts. The aerosols which escaped the ESP were trapped in a F72C Series oil removing coalescing filter (NORGREN, Littleton, CO). The clean noncondensable gases that exited the coalescing filter passed through a totalizer to measure the total volume of gases (nitrogen and pyrolysis gases) produced.

The liquid (organics/water) and solid (char/coke) product yields were determined gravimetrically by weighing the reactor, hot-gas-filter, water chilled condensers, and the ESP before and after each experiment. Each pyrolysis experiment lasted 2 hours and all experiments were replicated.

\subsection{Pyrolysis Oils Characterization}

The pyrolysis liquids collected from the condensers and the ESP were analysed for their moisture content. The moisture content was determined by volumetric Karl Fisher titration method using Metrohm 701KF Titrino (Brinkmann Instruments Inc., Westbury, NY) and a 703 titration stand and Hydranal ${ }^{\circledR}$ composite 5 reagent. The bio-oils collected in the ESP were used for further analysis since they had very low $(<1.0$ mass $\%)$ water content. The $\mathrm{pH}$ of the oils was measured using a Mettler Toledo SevenEasy $\mathrm{pH}$ meter and probe (Mettler-Toledo $\mathrm{GmbH}$, Switzerland). The $\mathrm{pH}$ values were taken after 7-10 min of stabilization of the mechanically stirred oil. The dynamic viscosity and density of the oils was measured at $40^{\circ} \mathrm{C}$ using SVM 3000 Stabinger viscometer (Anton Paar USA, Ashland, VA). The heating values were determined using the IKA C2000 basic bomb calorimeter. The elemental compositions of the pyrolysis oils were determined using Thermo Scientific Flash 2000 organic elemental analyzer. The sample size was $2-4 \mathrm{mg}$ and the oxygen content of the oils was determined by difference. The ${ }^{13} \mathrm{C}$ NMR spectra of the ESP oils were obtained using a JOEL $300 \mathrm{MHz}$ NMR spectrometer (JOEL Ltd, Tokyo, Japan). The ${ }^{13} \mathrm{C}$ NMR samples were prepared by dissolving 0.1-0.2 $\mathrm{g}$ of bio-oil in $0.7 \mathrm{~g}$ deuterated dimethylsulfoxide $\left(D_{M S O}-d_{6}\right)($ Sigma Aldrich, St. Louis, MO, USA). The pulse width was $14.75 \mu \mathrm{s}$ and the acquisition time was $1.57 \mathrm{~s}$ with a 2 seconds relaxation delay and 3000 scans were acquired.

The pyrolysis oils were also analyzed using Shimadzu GC/MS-QP2010S (Shimadzu Scientific, Columbia, MD). Compounds were separated using an HT5 GC column (30 m, $0.25 \mathrm{~mm} \mathrm{ID}$, and $0.10 \mu \mathrm{m}$ film thickness, SGE, Austin, TX). Helium was used as the carrier gas set to a constant velocity of $50 \mathrm{~cm} \mathrm{~s}^{-1}$. The injector temperature was set at $350^{\circ} \mathrm{C}$ and the injector split ratio set to $1: 2$. The column was initially set at a temperature of $60^{\circ} \mathrm{C}$ for $1 \mathrm{~min}$ and then increased to a temperature of $200^{\circ} \mathrm{C}$ at a rate of $5^{\circ} \mathrm{C} \mathrm{min}^{-1}$. The temperature was then raised to $340^{\circ} \mathrm{C}$ at a rate of $15^{\circ} \mathrm{C} \min ^{-1}$ and held at this temperature for $15 \mathrm{~min}$. A mass range of 45 to $500 \mathrm{~m} / \mathrm{z}$ was scanned at a rate of 1000 scans $s^{-1}$. Compounds were identified by comparing the mass fragment pattern of each resolved peak to the National Institute of Standards and Technology (NIST) 2005 mass spectral library (NIST, Gaithersburg, MD) using the software GC/MS postrun analysis v2.3 (Shimadzu Scientific, Columbia, MD).

\subsection{Pyrolysis Gas Analysis}

A Varian 490 micro GC (Agilent Technologies, Inc. Santa Clara, CA) was used to identify and quantify the noncondensable gases generated from the pyrolysis of the OMWS. During pyrolysis, $1 \mu \mathrm{L}$ of the gases from the slip stream of non-condensable gases was automatically injected into the micro GC and analyzed online every $10 \mathrm{~min}$. The micro GC was equipped with two channels: the first channel contained a $10 \mathrm{~m}$ Molsieve $5 \AA$ column, and the second channel contained a $10 \mathrm{~m}$ porous polymer column (PPU). Each module had a thermal conductivity detector. The MS column was used to analyze hydrogen, methane and carbon monoxide. Carbon dioxide and $\mathrm{C}_{1}-\mathrm{C}_{5}$ gases were analyzed by the PPU column. The identity and quantification of the gas components were accomplished by comparing the retention times with that of authentic standard gases obtained from Scott analyzed gases (Sulpeco, Bellefonte, PA) and using calibration curves to quantify the individual gases.

\section{Results and Discussions}

\subsection{Characteristics of OMWS Feedstock}

The exterior surface of the OMWS was hard and black with a strong offensive smell, but the interior was soft and sticky. The ground OMWS was sticky and did not flow readily and stuck to the screw feeder. The addition of $20 \mathrm{wt} \%$ silicon carbide improved the flow properties considerably and the mixture was easily fed by screw feeder into the pyrolysis reactor.

About 74 mass $\%$ of the OMWS was extractable with hexanes, ethanol, and water (Table 1) which indicate that the structural biopolymers (cellulose, lignin, and hemicellulose) content of the feedstock was very low. The hexane extract (HE) was semi-solid at room temperature, but became liquid when the sample bottle was held in the hand for a few minutes. This phase change behavior is typical of paraffins 
such as heptadecane, octadecane, eicosane and fatty acids such as palmitic, and stearic, which suggested that this fraction was rich in these compounds [26-28].

The volatile matter content was 84 mass $\%$. There appeared to be hardly any fixed carbon in this material which implies that potentially very high yields of pyrolysis oils could be obtained if cracking of the primary pyrolysis products into non-condensable gases was minimized. The ash content of the OMWS was high (15.2 wt\%) and was almost threefold higher than those reported for olive oil waste (crushed kernel and pulp) $[14,15,29]$, but similar to those reported for olive mill waste vegetation water [30]. In the studies conducted by Vitolo et al. [30], fresh effluents (vegetation water) that was not stored in open ponds was evaporated in a vacuum rotary evaporator to very high consistency and then dried in oven to produce solid residues; the ash contents of the effluent residues from the traditional batch and continuous threephase olive oil processing mills were 15 and 17 mass $\%$ respectively, while the olive husk had 1 mass $\%$. Thus, the high ash content obtained in the current feedstock cannot be attributed to either degradation of the organic material during storage or contamination from evaporation pond soil. The ash derived mostly from the wastewater or "vegetation water" as it is known in the industry.

Table 1. Characteristics of olive mill wastewater sludge (OMWS) from Sfax, Tunisia and OMWS hexane extract (All data are on moisture-free basis).

\begin{tabular}{lll}
\hline Parameters & OMWS & Hexane extract \\
\hline Hexane extract (mass\%) & 41.16 & \\
95\% ethanol extract (mass\%) & 19.81 & \\
Water extract (mass\%) & 13.38 & \\
Total extractives (mass\%) & 74.35 & \\
Moisture (mass\%) & 7.8 & \\
Volatile matter (mass\%) & 84.8 & \\
Ash (mass\%) & 15.2 & 4.39 \\
Carbon (mass\%) & 53.65 & 75.08 \\
Hydrogen (mass\%) & 7.10 & 11.64 \\
Nitrogen (mass\%) & 1.99 & 0.11 \\
Sulfur (mass\%) & 0.61 & bdl \\
Chlorine (mass\%) & 1.01 & nd \\
Oxygen (by difference) & 22.09 & 8.78 \\
HHV (MJ/kg) & 25.64 & 37.5 \\
Saponification value (mgKOH/g) & & 217 \\
Acid value (mgKOH/g) & & 129 \\
Ester value (mgKOH/g) & & 88 \\
Free fatty acid (\%) & & 64.9 \\
Glycerin (\%) & & 4.6 \\
Unsaponifiable (\%) & & 7.2 \\
\hline
\end{tabular}

The HHV of OMWS was higher than that of most lignocellulosic biomass feedstocks [31] because of the presence of free fatty acids (FFA) and unsaponifiable compounds from the vegetation water. Evidence of FFA and unsaponifiable compounds is shown by the high hexane extracts and the high aliphatic carbon signals observed in the hexane extracts as discussed below.

The acid number of the HE was $129 \mathrm{mgKOH} /$ (g extract); the saponification value was $217 \mathrm{mgKOH} /$ (g extract) and the calculated FFA was $65 \%$ (Table 1). The ester value was 88 and the glycerine value was $4.81 \%$. Thus, it is clear from the above values that the HE which constituted $41 \%$ of the OMWS was rich in FFA and low in glycerine probably because of the degradation during storage in the pond. The predominant FFA groups detected by GC/MS analysis of the HE were oleic and palmitic acids, which is similar to the findings of Saiz-Jaminez et al. [32]. The major compounds detected in the ethanol extract were glycerol, 2-methyl-1,3-cyclohexanedione and 4hydroxy-benzeneethanol, which clearly indicated that some of the triglycerides had been hydrolyzed into FFA and glycerol. The unsaponifiable material content was relatively low (7.2 mass\%). The ${ }^{13} \mathrm{C}$ NMR analysis of the HE showed strong signals for aliphatic carbons (Figure 1a) and comparison of the ${ }^{13} \mathrm{C}$ NMR spectrum with that of virgin olive oil (Figure 1b) confirmed the presence of acylglycerides in this extract. Additionally it appeared the HE also contained some sterols which were also detected in minor concentrations using GC/MS analysis. The four functional groups typical of virgin olive oil were identified in the HE; this included carbonyl compounds between $172 \mathrm{ppm}$ and $180 \mathrm{ppm}$ that correspond to monoacylglycerides (MAG), diacylglyderides (DAG), triacylglycerides (TAG), and FFA. The FFA signal at $180 \mathrm{ppm}$ was very weak whereas, the glycerol ester carbon signals at $172 \mathrm{ppm}$ due to MAG, DAG, and TAG were relatively stronger, but compared to virgin olive oil (Figure 1b), these peak intensities were very weak and indicates that the residual amount of acylglycerides was very low. Most of the signals appeared to be due to MAG and DAG according to assignments by Sacchi et al. [33] with very little contribution from TAG. The lipids content of olive mill wastewater is usually very low ranging from 1.6 to $9.8 \mathrm{~g} / \mathrm{L}$ [34], which appeared to support the weak signals observed for the HE. Further, it was reported that fats and carbohydrates in olive mill wastewater degraded when they were stored and converted to sludges in open ponds [3], but Saiz-Jimenez et al. [32] detected lipids in the studied OMWS. These apparent contradictory results suggest large variability in OMWS composition due to different pond storage conditions.

The unsaturated carbons in fatty acids and olefinic carbons in sterols, as well as aromatic hydrocarbons that resonate between 121 and $140 \mathrm{ppm}$ were detected in the hexane extract and the glycerol carbons, fatty alcohols, and carbon atoms bonded to hydroxyl group in sterols that have signal between 60 and $72 \mathrm{ppm}$ were also detected in the extract; however, the signals were relatively weak compared to the olive oil and there were other peaks also present. The aliphatic carbon region from 10-58 ppm was very strong since the FFA content of the HE was very high. The ${ }^{13} \mathrm{C}$ NMR of the alcohol soluble fraction and water soluble fraction showed very weak signals, probably because of poor solubility in the NMR solvent. Thus, the OMWS appeared to be FFA-rich feedstock compared to most lignocellulosic biomass feedstocks. 

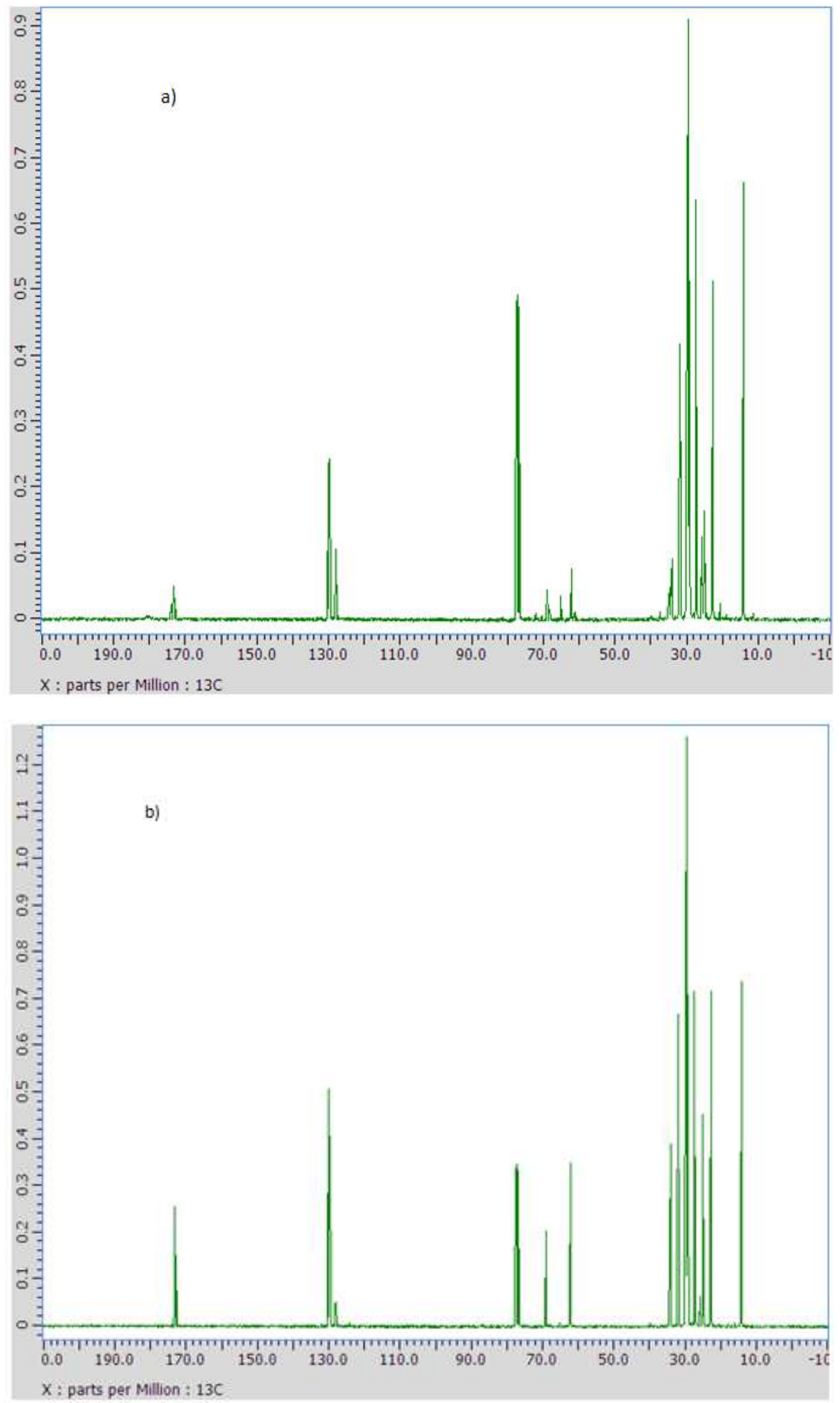

Figure $1 .{ }^{13}$ C NMR spectra of hexane soluble extractives and virgin olive oil: a) hexane soluble extractives, b) virgin olive oil. 


\subsection{OMWS Pyrolysis Products}

[13]The red mud water slurry had a $\mathrm{pH} 9$ and the dry ground material used for the experiments had a BET specific surface area $30 \mathrm{~m}^{2} / \mathrm{g}$. The XRF analysis of red mud showed the following major metal oxides (mass\%): $\mathrm{Fe}_{2} \mathrm{O}_{3}(53.98)$, $\mathrm{Al}_{2} \mathrm{O}_{3}$ (13.53), $\mathrm{SiO}_{2}$ (8.91), $\mathrm{CaO}$ (8.87), $\mathrm{TiO}_{2}$ (6.18), and $\mathrm{Na}_{2} \mathrm{O}(5.83)$ which were similar to those reported in literature [35]. The presence of these oxides was further confirmed with XRD analysis. The red mud was not activated before being used, thus, the reported catalytic effect is on as received basis. The red mud samples were heated in the reactor for almost two hours to achieve a stable pyrolysis temperature before each reaction. The red mud did not have any magnetic properties before the pyrolysis, but after pyrolysis it had magnetic properties. The change in properties of the red mud was attributed to the conversion of hematite $\left(\mathrm{Fe}_{2} \mathrm{O}_{3}\right)$ to magnetite $\left(\mathrm{Fe}_{3} \mathrm{O}_{4}\right)$ under the reducing pyrolysis conditions. This transformation of red mud after pyrolysis was described in detail in Yathavan and Agblevor [35].

The pyrolysis products distribution at various temperatures using red mud and sand are reported in Table 2. The oils collected in the condensers formed two phases with the aqueous fraction because of the low density of the oils and low oxygen content. The two phases were easily separated by decantation. The pyrolysis oils collected from the ESP had low water content and so there was only one phase and it also had very low viscosity, low density, and strong odor similar to the condenser oil. The red mud pyrolysis oils were liquids at room temperature independent of the pyrolysis temperature probably because they contained much shorter hydrocarbons chains from the catalytic cracking. The pyrolysis oils from the sand pyrolysis at $400^{\circ} \mathrm{C}$ and $450^{\circ} \mathrm{C}$ were semi-solids at room temperature, while the oils at $500^{\circ} \mathrm{C}$ were liquids.

The total liquid yields were only slightly affected by temperature variation between 400 and $500^{\circ} \mathrm{C}$. In general catalytic pyrolysis tends to decrease the yield of liquid products because of cracking of the organic fraction [35-39], the same decrease in liquid yield was observed in these studies, but the decrease appeared to be less severe compared to woody biomass pyrolysis using HZSM-5 zeolite and red mud catalysts Yathavan and Agblevor [35]

The temperature increase appeared to have minimal effect on the production of pyrolytic water from the organic liquids by the sand, instead it produced some gases. In contrast, the red mud pyrolysis converted a large fraction of the organic liquid products into pyrolytic water and thus reducing the organic liquid yield. The mechanism of liquid formation using the red mud was quite different from that due to the thermal process on the silica sand. Whereas the silica sand cracked the organic liquids to gases with minimal dehydration of the oxygenated compounds, in contrast, the red mud appeared to produce both pyrolytic water and gases from the cracking of the organic liquid through decarboxylation, ketonization, and decarbonylation reactions Yathavan and Agblevor [35].

The char/coke yield was affected by both temperature variation and red mud catalysis; whereas the silica sand showed only $7 \%$ decrease in yield, the red mud showed a slightly larger decrease $(10 \%)$ when the temperature was increased from $450^{\circ} \mathrm{C}$ to $500^{\circ} \mathrm{C}$. The slight difference in the char/coke yield was attributed to the catalytic effect of the red mud. The overall contribution of the red mud to char/coke formation was very low; most of the char/coke formation was attributed to thermal effect. The difference between the thermal effect and the catalytic effect on char/coke yield was almost constant at all pyrolysis temperatures (Table 2). At all temperatures the red mud pyrolysis produced less char/coke than the sand pyrolysis, which is contrary to what was observed for the pyrolysis of pinyon-juniper using red mud where there was very little difference between the char/coke yields using the two pyrolysis media [35].

Table 2. OMWS Pyrolysis product yields for red mud and silica sand pyrolysis media.

\begin{tabular}{lllllll}
\hline Pyrolysis medium & Sand & \multicolumn{5}{c}{ Red mud } \\
\hline Pyrolysis temp $\left({ }^{\circ} \mathbf{C}\right)$ & $\mathbf{4 0 0}$ & $\mathbf{4 5 0}$ & $\mathbf{5 0 0}$ & $\mathbf{4 0 0}$ & $\mathbf{4 5 0}$ & $\mathbf{5 0 0}$ \\
\hline Organic liquid (\%) & $33.1 \pm 0.5$ & $37.47 \pm 1.4$ & $30.4 \pm 1.9$ & $34.6 \pm 2.6$ & $29.8 \pm 1.4$ & $29.5 \pm 0.4$ \\
Pyrolytic water (\%) & $8.8 \pm 1.9$ & $7.93 \pm 1.8$ & $8.8 \pm 0.1$ & $11.3 \pm 1.8$ & $17.6 \pm 1.5$ & $11.8 \pm 0.9$ \\
Total liquid (\%) & $42.3 \pm 2$ & $45.4 \pm 0.4$ & $39.4 \pm 1.8$ & $45.9 \pm 4.4$ & $47.4 \pm 0.1$ & $42.3 \pm 1.3$ \\
Char/coke (\%) & $31.7 \pm 2.3$ & $25.7 \pm 0.3$ & $24.4 \pm 0.2$ & $29.1 \pm 1.8$ & $22.7 \pm 0.2$ & $20.4 \pm 0.4$ \\
Gas (\%) & $26.0 \pm 3.7$ & $29.3 \pm 1.0$ & $36.2 \pm 1.6$ & $24.3 \pm 2.6$ & $30.0 \pm 0.04$ & $37.3 \pm 1.7$ \\
\hline
\end{tabular}

The gas yields also had contributions from the thermal effect and the red mud catalysis. In the case of the silica sand, increasing temperature from $400^{\circ} \mathrm{C}$ to $500^{\circ} \mathrm{C}$ showed $39 \%$ increase in gas yields whereas in the case of the red mud there was corresponding 53\% increase in gas yield. The higher gas yield from the red mud was attributed to decarboxylation, decarbonylation and cracking of the organic liquid fraction.

\subsection{Properties of Liquid Pyrolysis Products}

The physicochemical properties of the OMWS pyrolysis oils are shown in Table 3. These properties were based on the oil fraction collected from the ESP because it contained the least amount of water and additionally the organic fractions separated from the condensers were similar to the ESP oils both chemically and physically. The pHs of the samples were measured from the condenser fraction and they were either 
neutral or slightly acidic and did not vary very much with pyrolysis temperature. In comparison to wood bio-oils, the $\mathrm{pHs}$ of these oils were very remarkable because a typical wood bio-oil $\mathrm{pH}$ is between 2.5 and 4.0 even when catalyst is used. Thus, we expect these oils to be less corrosive than the wood bio-oils.

Table 3. Properties of OMWS pyrolysis oils produced on silica sand and red mud pyrolysis media.

\begin{tabular}{|c|c|c|c|c|c|c|}
\hline \multirow{2}{*}{$\begin{array}{l}\text { Pyrolysis medium } \\
\text { Pyrolysis temp }\left({ }^{\circ} \mathrm{C}\right)\end{array}$} & \multicolumn{3}{|c|}{ Silica sand } & \multicolumn{3}{|c|}{ Red mud } \\
\hline & 400 & 450 & 500 & 400 & 450 & 500 \\
\hline $\mathrm{pH}$ & 6.5 & 6.25 & 6.4 & 7.1 & 7.3 & 7.4 \\
\hline Dynamic viscosity (cP) & 42.9 & 42.9 & 28.0 & 9.2 & 5.4 & 4.6 \\
\hline Density $\left(\mathrm{g} / \mathrm{cm}^{3}\right)$ & & 0.92 & 0.92 & 0.91 & 0.91 & 0.90 \\
\hline HHV (MJ/kg) & & 37.5 & 38.8 & 39.5 & 40.4 & 41.3 \\
\hline Carbon (mass\%) & 77.19 & 76.67 & 78.19 & 80.30 & 83.39 & 82.40 \\
\hline Hydrogen (mass \%) & 11.81 & 11.78 & 11.83 & 11.30 & 11.45 & 11.00 \\
\hline Oxygen $(\%)^{*}$ & 8.16 & 8.82 & 7.23 & 5.90 & 3.03 & 4.00 \\
\hline Sulfur (mass \%) & 0.00 & 0.00 & 0.00 & 0.00 & 0.00 & 0.00 \\
\hline Ash (mass\%) & 0.00 & 0.00 & 0.00 & 0.00 & 0.00 & 0.00 \\
\hline
\end{tabular}

*Oxygen by difference.

The viscosities of the oils were strongly affected by the red mud catalysis and less by the pyrolysis temperature. The sand pyrolysis oils were more than fourfold viscous than those produced using the red mud as catalyst at the same temperature (Table 3 ). The red mud was very effective in cracking the high molecular weight components of the OMWS pyrolysis products to low molecular weight components and thus reducing the viscosity considerably. When red mud was also used for the catalytic pyrolysis of pinyon-juniper wood it showed over seven-fold decrease in the viscosity of the pyrolysis oils relative to sand pyrolysis oils [35] Thus, it appears the effectiveness of red mud catalytic pyrolysis in the reduction of the viscosities of the pyrolysis oils is feedstock dependent. The increases in pyrolysis temperatures caused only slight decrease in the viscosity of the pyrolysis oils in either the sand or red mud pyrolysis conditions. The oils showed some slight increase in viscosity after storage at ambient conditions for three months.

The HHVs of the oils were very high compared to the starting material and wood bio-oils. The major differences between the starting material and the pyrolysis oils were the absence of ash and lower oxygen content in the pyrolysis oils compared to higher oxygen content and 15.2 mass $\%$ ash of the OMWS raw material. On ash-free and moisture-free basis, the raw OMWS had HHV of $30.36 \mathrm{MJ} / \mathrm{kg}$ and $24.1 \mathrm{mass} \%$ oxygen, so that during pyrolysis, there was considerable deoxygenation. The raw OMWS oxygen content was reduced from 24.1 mass $\%$ to 5 mass $\%$ after pyrolysis at $450^{\circ} \mathrm{C}$, which is equivalent to $79.2 \%$ deoxygenation of the OMWS by the red mud. The HHV of the red mud catalyzed pyrolysis oil ranged from 39.5-41.3 MJ/kg which is lower than that of D2petrodiesel (42 MJ/kg) but higher than that of biodiesel (37.3 $\mathrm{MJ} / \mathrm{kg}$ ) [40]. A typical biodiesel fuel contains 10-12 mass\% oxygen compared to the 5 mass $\%$ obtained for the OMWS red mud pyrolysis oil.

The ${ }^{13} \mathrm{C}$ NMR analyses of the pyrolysis oils and semiquantitative integration of the NMR spectra are shown in Table 4. The spectra show major functional groups in aliphatic, aromatic, carboxylic, and carbonyl regions. There were major differences in the spectra of the non-catalytic (sand) and red mud catalyzed pyrolysis oils which corroborates the physicochemical properties described above. The sand pyrolysis oil spectrum showed strong resonance for aliphatic carbon for both long and short chain compounds (10-50 ppm). The integrated data (Table 4) showed that the intensity of the aliphatic carbons chemical shift for the sand pyrolysis oils were much higher than those for the red mud pyrolysis oils except at $400^{\circ} \mathrm{C}$, which suggested that the red mud was more effective in cracking the aliphatic carbon chains. This is corroborated by the relative decrease in the intensity of signals of $\mathrm{CH}_{2}$ carbons (29-30 ppm), allylic and diallylic carbons (25-27 ppm) for the red mud compared to the sand After pyrolysis on the sand, the intensities of the $\mathrm{CH}_{2}$ and allyl peaks were considerably reduced, but the $\mathrm{CH}_{2}$ peak was still dominant. In the case of the red mud pyrolysis, the allylic carbon signals were very weak and there was drastic reduction in the intensity of the $\mathrm{CH}_{2}$ signal. In this case, the $\mathrm{CH}_{3}$ signal was the major peak at all pyrolysis temperatures. At $400^{\circ} \mathrm{C}$, there was a drastic reduction in both the $\mathrm{CH}_{2}$ and allylic signals, but the $\mathrm{CH}_{3}$ signal was slightly stronger than the $\mathrm{CH}_{2}$ signal because the red mud is less active at this temperature. At $450^{\circ} \mathrm{C}$ and $500^{\circ} \mathrm{C}$, where the red mud is most active, the $\mathrm{CH}_{2}$ signal was much weaker and the dominant peak was $\mathrm{CH}_{3}$. These data clearly show that red mud was more effective in cracking the oils than the thermal process, thus shortening the $\mathrm{CH}_{2}$ carbon chain length. More short chain aliphatic carbons were produced than the sand pyrolysis and hence the higher intensity of the $\mathrm{CH}_{3}$ carbon signals for red mud catalytic pyrolysis oils compared to sand oils. This also partially accounts for the drastic reduction in the viscosity of the red mud OMWS pyrolysis oils.

The red mud appeared to have converted some of the aliphatic carbons to aromatic compounds which contributed to the increased intensity of the aromatic carbon signals (Table 4). It is known that zeolites and metal oxides such as titanium, chromium, molybdenum and mixtures of metal oxides can convert straight chain aliphatic hydrocarbons to aromatic compounds through dehydrogenation cyclization 
reaction pathways [41-44]. The high hydrogen content of the gases (Table 7) also corroborates this assertion. The gas produced at all temperatures using red mud had hydrogen content over four times higher than those produced using the sand, which implies that there were dehydrogenation reactions due to red mud catalysis to produce olefins that underwent further cyclization reactions producing aromatic compounds and releasing more hydrogen in the process.

The oxygenated aliphatic compounds region (50-110 ppm) showed very weak resonances compared to those observed for the hexane extract (Figure 1a) suggesting that some of the glycerol, alcoholic, and sterol compounds were converted to other compounds during the pyrolysis. Although there were weak signals in the 50-110 ppm region for the sand pyrolysis oils at $450^{\circ} \mathrm{C}$, in the case of the red mud pyrolysis oils, there were no signals. This clearly showed that the red mud was effective in deoxygenating these compounds or converted them into coke or gas. In the olefinic and aromatic carbons region of the spectra (110-160 ppm), the olefinic signals at 129-130 ppm were more intense for the sand pyrolysis oils relative to the red mud pyrolysis oils, which indicate that the sand was not effective in converting the double bond compounds, whereas the red mud broke some of these bonds and/or converted them into aromatic compounds through dehydrogenation and cyclization. The semi-quantitative integration of the ${ }^{13} \mathrm{C}$ NMR data showed that at similar pyrolysis temperatures, the aromatic compounds produced with the red mud were twofold higher than that produced using the sand.

The carboxylic carbon region was relatively intense for the sand pyrolysis oil and very weak for the red mud pyrolysis oils. Thermal cracking did not produce any significant decarboxylation of the carboxylic groups, but the red mud was effective in converting the carboxylic compounds to other products and therefore the peak for the sand pyrolysis oils were greater than that for the red mud at the same temperature. It is interesting to note that whereas in the hexanes extract the carboxylic carbon signal at $172 \mathrm{ppm}$ was attributed to glycerol ester, after pyrolysis in both the sand and red mud, the signal shifted to $174.5 \mathrm{ppm}$ which is typical of alkyl ester carbon. Saiz-Jimenez et al. [32] also observed esterified $\mathrm{C} 16$ and $\mathrm{C} 18$ fatty acids in the products of flash pyrolysis GC-MS studies of OMWS, which is in agreement with our data.

Table 4. Semi-quantitative integration of ${ }^{13} \mathrm{C} N M R$ spectra of OMWS pyrolysis oils produced at various temperatures on red mud and sand pyrolysis media (signal area).

\begin{tabular}{|c|c|c|c|}
\hline Functional groups & Chemical shift (ppm) & Sand@400 & Sand@450 \\
\hline carbon in aliphatic chains & $0-50$ & 1956 & 4858 \\
\hline aliphatic carbon substituted by oxygen and/or nitrogen & $50-110$ & 36 & 39 \\
\hline olefinic and aromatic carbon & $110-160$ & 254 & 432 \\
\hline carboxylic carbon in ester, acids or amide & $160-180$ & 32 & 116 \\
\hline carbon in aldehydes and ketones & $180-220$ & 0 & 0 \\
\hline
\end{tabular}

Table 4. Continued.

\begin{tabular}{|c|c|c|c|c|}
\hline Functional groups & Sand@500 & Red mud@400 & Red mud@450 & Red mud@500 \\
\hline carbon in aliphatic chains & 4065 & 2530 & 2093 & 1893 \\
\hline aliphatic carbon substituted by oxygen and/or nitrogen & 25 & 24 & 12 & 7 \\
\hline olefinic and aromatic carbon & 314 & 571 & 859 & 840 \\
\hline carboxylic carbon in ester, acids or amide & 59 & 29 & 18 & 12 \\
\hline carbon in aldehydes and ketones & 0 & 20 & 12 & 4 \\
\hline
\end{tabular}

There were ketonization reactions during red mud pyrolysis of the OMWS but none occurred during the sand pyrolysis oils a shown by the peaks detected in the pyrolysis oils (Table 4). Ketonization reactions which produce water and ketones (Eq. 1) can be catalyzed by metal oxides such as $\mathrm{MgO}, \mathrm{TiO}_{2}, \mathrm{Fe}_{3} \mathrm{O}_{4}, \mathrm{CaO}$, activated $\mathrm{Al}_{2} \mathrm{O}_{3}$ and mixed oxides [45-47]. The red mud used in these studies contained most of the above metal oxides which will explain the formation of ketones.

$$
2 \mathrm{RCO}_{2} \mathrm{H}=\mathrm{RCOR}+\mathrm{CO}_{2}+\mathrm{H}_{2} \mathrm{O}
$$

The GC/MS analyses of the liquid products from the sand and red mud catalytic pyrolysis are reported in Tables 5 and 6. The sand pyrolysis oils showed the high contents of fatty acids such as oleic and palmitic acids as well as esters and hydrocarbons (Table 5). In contrast, there were no free fatty acids in the red mud catalytic pyrolysis oils, but instead there were esters, ketones, alcohols, nitriles, alkane, and alkyne hydrocarbons (Table 6). The presence of decane, 1-undecene, undecane, and other shorter chain hydrocarbons show that the red mud was not only effective in deoxygenating the fatty acids but it was also effective in partially cracking the long chain hydrocarbons into shorter chain hydrocarbons. Pyrolysis of oleic acid using red mud (data not reported) also confirmed the above results because ketones, alcohols, esters and aromatic compounds were produced.

\subsection{Effect of Temperature on Red Mud Pyrolysis of OMWS}

The pyrolysis temperature had very considerable effect on the properties of the OMWS pyrolysis oils using red mud as catalyst. In Table 3, it can be clearly seen that increasing the pyrolysis temperature from $400^{\circ} \mathrm{C}$ to $500^{\circ} \mathrm{C}$ had considerable effect on viscosity and higher heating values of the pyrolysis oils. The viscosity of the oil decreased from $9.2 \mathrm{cP}$ at $400^{\circ} \mathrm{C}$ to $5.4 \mathrm{cP}$ at $450^{\circ} \mathrm{C}$ and at $500^{\circ} \mathrm{C}$ the viscosity was $4.6 \mathrm{cP}$ which showed the effectiveness of the red mud in cracking the higher molecular weight products to produce low viscosity liquids. The densities of the oils were not 
significantly affected by the increase in the pyrolysis temperature. The HHVs of the oils increased slightly with increase in the red mud pyrolysis temperature. The HHV increased from $39.5 \mathrm{MJ} / \mathrm{kg}$ at $400^{\circ} \mathrm{C}$ to $41.3 \mathrm{MJ} / \mathrm{kg}$ at $500^{\circ} \mathrm{C}$ pyrolysis temperature.

The chemical composition of the red mud OMWS pyrolysis oils showed considerable variation between the $400^{\circ} \mathrm{C}, 450$ and $500^{\circ} \mathrm{C}$ oils. In general the 450 and $500^{\circ} \mathrm{C}$ oils were similar. The $400^{\circ} \mathrm{C}$ had the highest aliphatic carbon content and high levels of carboxylic carbon signals (Table 4). The olefinic and aromatic carbon signals at $400^{\circ} \mathrm{C}$ were relatively low compared to those at 450 and $500^{\circ} \mathrm{C}$, suggesting that the red mud was less active at $400^{\circ} \mathrm{C}$ in the dehydrogenation and production of aromatic compounds, but was maximum at $450^{\circ} \mathrm{C}$. This assertion is also borne out by the highest hydrogen content of the pyrolysis gases at $450^{\circ} \mathrm{C}$ (Table 7). Konar et al. [10] and Vonghia et al. [47] showed that activated alumina could deoxygenate sewage sludge lipids to produce straight chain alkanes and alkenes, a similar mechanism could be used to explain the production of aliphatic hydrocarbons in the OMWS using red mud because the red mud contains alumina, although we do not know the exact nature of the compound.

Ketone formation reactions appeared to be favoured by lower red mud pyrolysis temperatures because the signal was highest at $400^{\circ} \mathrm{C}$ and lowest at $500^{\circ} \mathrm{C}$. It has been reported that ketonization of short chain carboxylic acids (acetic, propionic) catalyzed by $\mathrm{TiO}_{2}$ and $\mathrm{Fe}_{3} \mathrm{O}_{4}$ occur between 370 and $450^{\circ} \mathrm{C}$ [46]. Leung et al. [48] also reported ketonization of long chain carboxylic acids using activated alumina at $450^{\circ} \mathrm{C}$. The above results are in agreement with the current studies. Carboxylic carbon signals were also highest at lower temperatures even in the absence of red mud catalyst. At the low temperatures, the activity of the red mud catalyst appeared very low and therefore both decarboxylation and ketonization reactions were low and hence the higher carboxylic carbon signal. In case of the sand there was no thermal decarboxylation reaction.

Table 5. Major GC/MS peaks (>1\%) of OMWS pyrolysis oils produced using silica sand pyrolysis medium.

\begin{tabular}{llll}
\hline No. & Retention time (min) & Peak Report (TIC Area\%) & Chemical compound \\
\hline 1 & 14.15 & 1.29 & Pentadecane \\
2 & 16.38 & 1.60 & 8-Heptadecene \\
3 & 16.45 & 1.27 & 1-Heptadecene \\
4 & 18.92 & 1.98 & Heptadecane \\
5 & 19.62 & 7.28 & Hexadecanoic acid \\
6 & 19.85 & 2.75 & Hexadecanoic acid, ethyl ester \\
7 & 20.75 & 1.88 & Unknown \\
8 & 20.79 & 3.33 & Unknown \\
9 & 20.93 & 4.62 & 9-Octadecenoic acid $(Z)$, methyl ester \\
10 & 21.48 & 28.54 & Oleic acid \\
11 & 21.58 & 9.72 & Ethyl oleate \\
12 & 21.81 & 5.85 & Unknown \\
13 & 22.35 & 2.22 & Unknown \\
14 & 22.47 & 2.39 & \\
\hline
\end{tabular}

Table 6. Major GC/MS peaks (>1\%) of OMWS red mud catalytic pyrolysis oil.

\begin{tabular}{llll}
\hline Peak No & Retention time & Peak Report (TIC Area\%) & Chemical compound \\
\hline 1 & 16.44 & 1.18 & 1-Decene \\
2 & 19.64 & 0.84 & p-cresol \\
3 & 21.59 & 2.15 & 1-undecene \\
4 & 22.17 & 1.47 & undecane \\
5 & 22.27 & 1.51 & 5-undecene \\
6 & 23.04 & 1.37 & 5,6 undecadiene \\
7 & 24.16 & 0.94 & 4-ethyl phenol \\
8 & 25.70 & 1.34 & 2-dodecanone \\
9 & 26.55 & 2.18 & 1-tridecene \\
10 & 27.01 & 1.22 & dodecane \\
11 & 27.92 & 1.67 & 8-dodecene-1-ol \\
12 & 31.27 & 2.02 & n-tridecan-1-ol \\
13 & 31.78 & 2.82 & hexadecane \\
14 & 35.72 & 4.28 & 1-tetradecene \\
15 & 36.19 & 2.04 & tetradecane \\
16 & 39.92 & 7.99 & n-pentadecanol \\
17 & 40.35 & 4.47 & heptadecane \\
18 & 42.04 & 1.39 & n-nonylcyclohexane \\
19 & 43.18 & 1.72 & n-pentadecanol \\
20 & 43.45 & 1.26 & heptadecane \\
21 & 44.81 & 8.0 & 9-octadecene-1-ol \\
22 & 45.02 & 6.0 & 3-heptadecene \\
23 & 45.30 & 3.35 & n-nonadecanol-1 \\
24 & 45.49 & 2.02 & heptadecane \\
\hline
\end{tabular}




\begin{tabular}{llll}
\hline Peak No & Retention time & Peak Report (TIC Area\%) & Chemical compound \\
\hline 25 & 48.03 & 1.67 & Hexadecane nitrile \\
26 & 48.20 & 3.98 & 2-heptadecanone \\
27 & 50.12 & 4.80 & oleanitrile \\
28 & 50.21 & 5.48 & heptadecyl oxirane \\
29 & 50.43 & 4.50 & 9-octadecanoic acid ethyl ester \\
30 & 52.02 & 1.19 & Oleic acid butyl ester \\
31 & 54.86 & 1.72 & 9-heptadecanone \\
\hline
\end{tabular}

\subsection{Pyrolysis Gases}

The composition of the pyrolysis gases at different temperatures and using different pyrolysis media are shown in Table 7. The pyrolysis gas components were similar for all the pyrolysis media, but varied in their individual concentrations. All pyrolysis gases contained $\mathrm{H}_{2}, \mathrm{CO}, \mathrm{CO}_{2}$, and $\mathrm{C}_{1}-\mathrm{C}_{5}$ hydrocarbons with $\mathrm{CO}$ and $\mathrm{CO}_{2}$ constituting 75-84 mass $\%$ of all gases. The extremely high $\mathrm{H}_{2}$ content of OMWS pyrolysis gases is unusual compared to most biomass pyrolysis gases. The hydrogen content ranged from 0.4 to 3.88 mass $\%$ or 15 to 44 vol\% of the gases. This high $\mathrm{H}_{2}$ yields were attributed to several reactions including thermal cracking, dehydrogenation, and cyclization promoted by the metal oxides in the red mud. It has been reported that activated $\mathrm{Al}_{2} \mathrm{O}_{3}$ catalyzed the conversion of lipids to alkenes
$[10,45]$ and $\mathrm{Fe}_{2} \mathrm{O}_{3}$ catalyzed dehydrogenation of alkenes to aromatic compounds [42]. Paraffins can also be converted into aromatic compounds, but this is preceded by dehydrogenation to olefins followed by cyclization [42, 44]. Since the red mud contains $\mathrm{Al}_{2} \mathrm{O}_{3}, \mathrm{Fe}_{2} \mathrm{O}_{3}, \mathrm{TiO}_{2}, \mathrm{CaO}$, and other metal oxides, it is plausible that these oxides promoted the formation of the $\mathrm{H}_{2}$ from the residual lipids in the OMWS. Boocock et al. [45] and Konar et al. [10] reported the production of hydrocarbons from sewage sludge lipids and triglycerides, but did not report the production of large quantities of hydrogen, probably because their catalyst was activated alumina which could not dehydrogenate the alkenes. Pyrolysis of virgin olive oil using red mud produced significant quantities of hydrogen (data not reported) thus confirming the above hypothesis.

Table 7. Composition of pyrolysis gases generated from sand and red mud OMWS pyrolysis at various temperatures (mass\%).

\begin{tabular}{|c|c|c|c|c|c|c|}
\hline Pyrolysis media & Silica sand & & & Red mud & & \\
\hline Pyrolysis temp $\left({ }^{\circ} \mathrm{C}\right)$ & 400 & 450 & 500 & 400 & 450 & 500 \\
\hline $\mathrm{H}_{2}$ & $0.45 \pm 0.03$ & $0.8 \pm 0.1$ & $1.1 \pm 0.1$ & $2.15 \pm 0.03$ & $3.8 \pm 0.3$ & $3.88 \pm 0.1$ \\
\hline $\mathrm{CO}$ & $4.7 \pm 0.1$ & $6.3 \pm 0.4$ & $6.0 \pm 0.6$ & $5.9 \pm 0.2$ & $7.3 \pm 0.01$ & $10.9 \pm 0.9$ \\
\hline $\mathrm{CO}_{2}$ & $81.1 \pm 2.6$ & $76.6 \pm 1.4$ & $74.6 \pm 0.7$ & $78.5 \pm 0.1$ & $72.5 \pm 0.9$ & $65.2 \pm 1.5$ \\
\hline $\mathrm{CH}_{4}$ & $1.5 \pm 0.4$ & $2.1 \pm 0.2$ & $2.6 \pm 0.2$ & $1.6 \pm 0.2$ & $2.6 \pm 0.1$ & $3.8 \pm 0.04$ \\
\hline $\mathrm{C}_{2}-\mathrm{C}_{5}$ & $10.5 \pm 1.9$ & $11.5 \pm 1.5$ & $13.3 \pm 0.8$ & $10.0 \pm 1.1$ & $10.8 \pm 0.9$ & $13.6 \pm 0.9$ \\
\hline Other hydrocarbons & $1.9 \pm 0.5$ & $2.8 \pm 0.2$ & $2.5 \pm 0.5$ & $1.9 \pm 0.3$ & $2.9 \pm 0.6$ & $2.6 \pm 0.5$ \\
\hline
\end{tabular}

The carbon dioxide production from the OMWS sand pyrolysis was attributed to thermal cracking while that from OMWS red mud catalytic pyrolysis was attributed to both thermal and catalytic cracking. In both the sand and red mud OMWS pyrolysis, the highest yield of $\mathrm{CO}_{2}$ occurred at the lowest temperature and decreased with increasing pyrolysis temperature (Table 7). The catalytic rejection of $\mathrm{CO}_{2}$ from the biomass can occur through ketonization, decarboxylation, or both pathways. In the case of red mud OMWS pyrolysis, a significant amount of ketones was produced at $400^{\circ} \mathrm{C}$ and $450^{\circ} \mathrm{C}$, but lesser amounts were produced at $500^{\circ} \mathrm{C}$ as shown by the ${ }^{13} \mathrm{C}$ NMR spectra of the pyrolysis oils (Table 4). However, at $500^{\circ} \mathrm{C}$, ketone signals in the pyrolysis oils were very weak but there was still production of $\mathrm{CO}_{2}$ at lower concentrations; this suggests that at this temperature $\mathrm{CO}_{2}$ production was dominated by decarboxylation reactions instead of ketonization. At $450^{\circ} \mathrm{C}$, activated alumina has been shown to catalyze ketonization reactions producing ketones and $\mathrm{CO}_{2}$ from carboxylic acids [48]. Other researchers [49-51] also reported ketonization reactions which corroborate our explanation.

The higher $\mathrm{CO}_{2}$ production from the red mud catalyzed pyrolysis could also be due to contribution from water gas shift reaction and the reduction of hematite to magnetite. We also observed water gas shift reaction when of water and $\mathrm{CO}$ were injected into into a fluidized bed containing red mud catalyst. The major products were $\mathrm{H} 2$ and $\mathrm{CO}_{2}$ with minor quantities of hydrocarbons and this reaction was attributed to the presence of $\mathrm{Fe}_{2} \mathrm{O}_{3}$ and $\mathrm{Fe}_{3} \mathrm{O}_{4}$ in the red mud catalyst. Jozwiak, et al. [52] reported that under low hydrogen and $\mathrm{CO}$ concentrations at $150-400^{\circ} \mathrm{C}$ and atmospheric pressure, hematite was converted to magnetite with the subsequent release of $\mathrm{CO}_{2}$ and $\mathrm{H}_{2} \mathrm{O}$ as shown in equations 2 and 3. The pyrolysis gas composition showed the presence of both $\mathrm{H}_{2}$ and $\mathrm{CO}$ and the red mud after pyrolysis had magnetic properties; thus it is plausible that some of the $\mathrm{CO}_{2}$ originated from the reduction of hematite to magnetite. The XRD data of the red mud after the pyrolysis also confirmed the formation of magnetite [35]

$$
\begin{aligned}
& 3 \mathrm{Fe}_{2} \mathrm{O}_{3}+\mathrm{H}_{2}=2 \mathrm{Fe}_{3} \mathrm{O}_{4}+\mathrm{H}_{2} \mathrm{O} \\
& 3 \mathrm{Fe}_{2} \mathrm{O}_{3}+\mathrm{CO}=2 \mathrm{Fe}_{3} \mathrm{O}_{4}+\mathrm{CO}_{2}
\end{aligned}
$$

The contribution of $\mathrm{CO}_{2}$ from the reduction of hematite to magnetite was presumed minimal because reaction (3) is very 
rapid and the $\mathrm{CO}_{2}$ will be released within a few minutes from the start of the pyrolysis reaction. Furthermore, this assertion is supported by the regenerated catalyst (magnetite/hematite) pyrolysis data which had similar $\mathrm{CO} / \mathrm{CO}_{2}$ ratio for the fresh and regenerated catalyst pyrolysis (Yathavan and Agblevor, 2013) [35]

The CO content was low and similar for both sand and red mud pyrolysis and showed very little variation with increase in pyrolysis temperature except at $500^{\circ} \mathrm{C}$ where the red mud $\mathrm{CO}$ production was quite high (10 mass\%). The low CO production suggests that decarbonylation reaction did not play major role in these reactions at the lower temperatures except at $500^{\circ} \mathrm{C}$.

The $\mathrm{C}_{2}-\mathrm{C}_{5}$ hydrocarbons yields did not appear to be significantly affected by the pyrolysis medium. The yields from the red mud at various temperatures appeared to be similar. However, there appeared to be slight increases in the yields at higher temperature $\left(500^{\circ} \mathrm{C}\right)$. The yields of other light hydrocarbons that were not identified also appeared to be similar at all temperatures and appeared to be independent of the pyrolysis medium.

\subsection{Environmental Impact of Technology}

The disposal of olive mill wastewater (OMW) is a major challenge in the olive oil producing countries because of the high phenolic compound content, high chemical oxygen demand (COD), and biological oxygen demand (BOD) values $[1,4]$. The major disposal methods such as evaporation storage ponds and land applications have been reported to have adverse impact on the soil because of phytotoxicity and therefore there have been suggestions to control the application of the OMW to agricultural lands [57]. This adverse environmental impact of OMW suggests that alternative disposal methods have to be developed to dispose of these materials. The pyrolysis technology discussed above has the potential to solve the disposal problem if it is combined with the evaporation storage pond method. The pyrolysis oils produced from the OMWS have relatively high yields, very high HHV, low viscosity, low density, and contain both aromatic and aliphatic compounds which will make them ideal for diesel fuel applications. Unlike most lignocellulosic biomass pyrolysis oils that contain mostly aromatic compounds and low levels of long chain aliphatic compounds, the OMWS red mud catalytic pyrolysis oils have high long chain aliphatic hydrocarbons content and relatively low aromatic hydrocarbon content. Therefore, these oils could find wider application as standalone fuels or blending stocks.

The other byproducts such as the biochar and the gases are also important. Because of the high $\mathrm{H}_{2}$ content of the gases, this will be used as fuel for the pyrolysis process (Figure 2), and the biochar which has concentrated nutrients such as $\mathrm{K}$ and $\mathrm{P}$ could be used as fertilizer ingredients without the attendant phytotoxicity problems and/or used in the process to improve the flow properties of OMWS for feeding into the pyrolysis reactor.

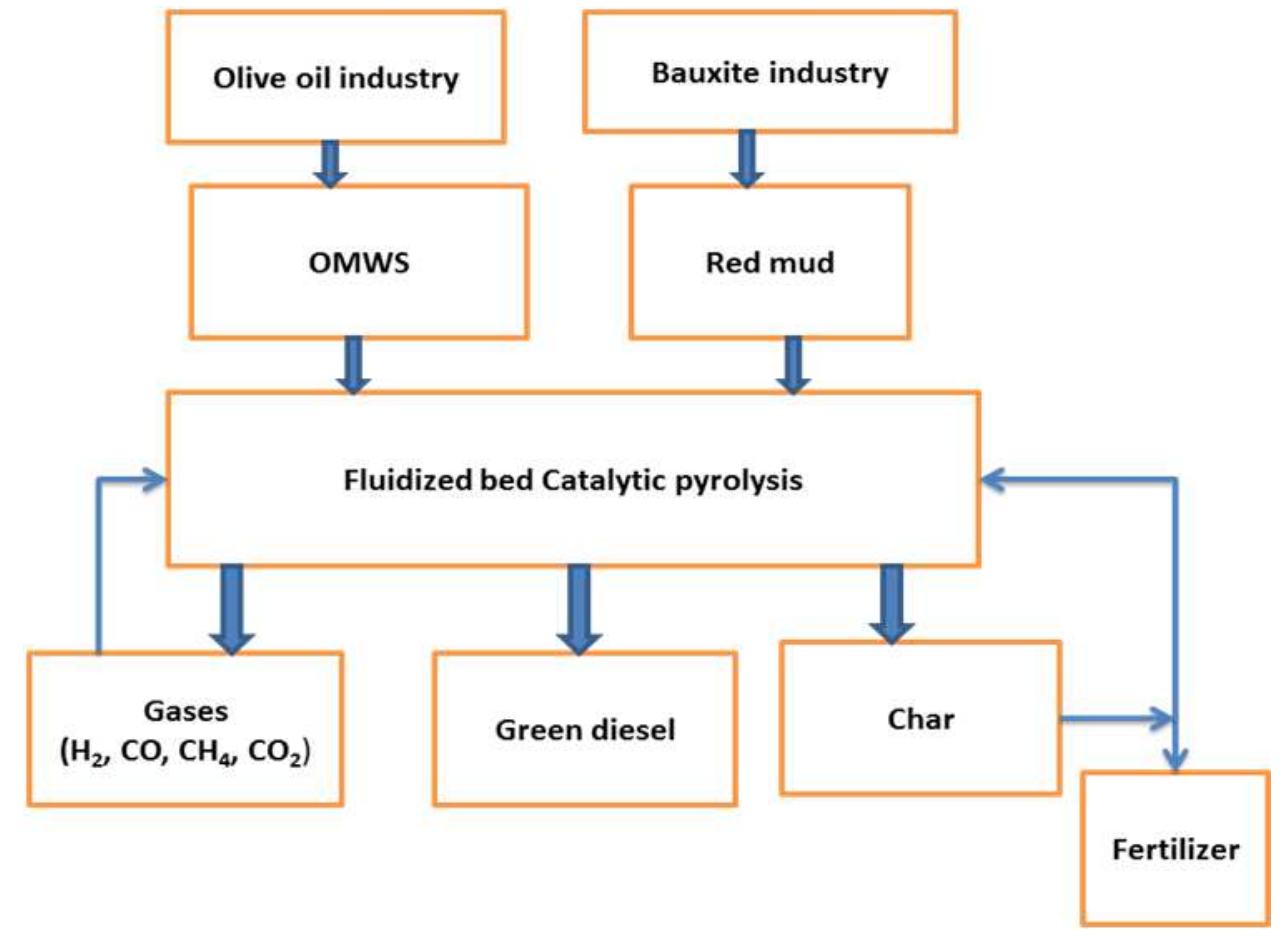

Figure 2. Schematic diagram of OMWS catalytic pyrolysis technology using red mud waste as catalyst.

Equally interesting about this technology is the use of red mud as an effective pyrolysis medium. Red mud like OMWS is an environmental pollutant that is similarly disposed in large storage ponds near bauxite processing facilities. The disposal of red mud has been a major challenge for the industry worldwide and there has been intensive research to find uses for this material. Our studies clearly show that the red mud will be an effective catalyst for converting OMWS to biofuel 
in a fluidized bed reactor. The red mud was also found to be an effective catalyst for the pyrolysis of pinyon-juniper. Red mud can therefore be processed as useful catalyst for biomass conversion. This approach to apparent waste utilization not only solves environmental pollution problems but converts the apparent waste materials into high value products.

\section{Conclusions}

The fast pyrolysis of OMWS using sand and red mud was investigated and it clearly showed that low viscosity, low density, high $\mathrm{pH}$, and high $\mathrm{HHV}$ oils can be produced from this feedstock. The quality of oils produced from OMWS when red mud was used as catalyst appeared to be better than biodiesel and had much lower oxygen content and high aliphatic hydrocarbon content compared to most lignocellulosic biomass pyrolysis oils. The red mud OMWS catalytic pyrolysis also produced high concentrations of hydrogen gas because of dehydrogenation and cyclization reactions catalyzed by some of the red mud metal oxide components and this hydrogen gas could be used to hydrogenate the oils to further reduce the oxygen content. This technology has the potential of addressing the olive mill wastewater disposal problems while simultaneously generating green diesel fuel.

\section{Acknowledgements}

The Utah Science Technology and Research (USTAR) Program is acknowledged for funding support. Sherwin Alumina Company LLC, Gregory TX is acknowledged for providing samples of red mud for the research. Drs S. S. Kim, Department of Chemical Engineering, Kangwon National University, Korea and V. Paasikallio, VTT Technical Research Center, Espoo, Finland are acknowledged for assisting in the GC/MS analysis of some of the samples.

\section{References}

[1] Mekki, A., Dhouib, A., Sayadi, S. (2007). Polyphenols dynamics and phytotoxicity in a soil amended by olive mill wastewaters. J. Environ. Management 84, 134-140.

[2] Roig, A., Cayuela, M. L., Sanchez-Monedero, M. A. (2006). An overview on olive mill wastes and their valorization methods. Waste and Management, 26, 960-969.

[3] Paredes, C., Cegarra, J., Roig, A., Sanchez, M. A., Bernal, M. P. (1999). Characterization of olive mill wastewater (alpechin) and its sludge for agricultural purposes. Bioresource Technol. 67, 111-115.

[4] Kavvadias, V., Doula, M. K., Komnitsas, K., Liakopoulou, N. (2010). Disposal of olive wastes in evaporation ponds: effects on soil properties. J. Hazarous Matl, 82, 144-155.

[5] Piotrowska, A., Iamarino, G., Rao, M. A., Gianfreda, L.(2006) Short-term effects of olive mill waste water (OMW) on chemical and biochemical properties of semiarid Mediterranean soil. Soil Biol. Biochem., 38, 600-610
[6] Mekki, A., Dhouib, A., Feki, F., Sayadi, S. (2008). Assessment of toxicity of the untreated and treated olive mill wastewaters and soil irrigated by using microbiotests. Ecotoxicology Environ. Safety, 69, 488-495.

[7] Barbera, A. C., Maucierri, C., Cavalaro, V., Ioppolo, A., Spagna, G. (2013). Effects of spreading olive mill wastewater on soil properties and crops, a review. Agricultural Waste Management, 119, 43-53.

[8] Boocock, D. G. B., Konar, S. K., Leung, A., Ly, L. D. (1992). Fuels and chemicals from sewage sludge 1. The solvent extraction and composition of a lipid from a raw sewage sludge. Fuel, 71, 1283-1289.

[9] Agblevor, F. A., Beis, S., Kim, S. S., Tarrant, R., Mante, O. (2010a) Biocrude oil from fast pyrolysis of poultry litter and hardwood. Waste Management, 30, 298-307.

[10] Konar, S. K., Boocock, D. G. B., Mao, V., Liu, J. (1995). Fuels and chemicals from sewage sludge: 3. Hydrocarbon liquids from catalytic pyrolysis of sewage sludge lipids over activated alumina. Fuel, 73 (5), 642-646.

[11] Mante, O. D. \& Agblevor, F. A. (2010). Influence of pine wood shavings on the pyrolysis of poultry litter. Waste Management, 30, 2537-2547.

[12] Fonts, I., Gea, G., Azuara, M., Abrego, J., Arauzo, J. (2012). Sewage sludge pyrolysis for liquid production: a review. Renewable and Sustainable Energy Reviews, 16, 2781-2805.

[13] Zabaniotou, A. A., Kalogiannis, G., Kappas, E., Karabelas, A. J. (2000). Olive residues (cuttings and kernels) rapid pyrolysis product yields and kinetics. Biomass \& Bioenergy, 18, 411420.

[14] Uzun, B. B., Putun, A. E., Putun, E. (2007). Composition of products obtained via fast pyrolysis of olive-oil residue: Effect of pyrolysis temperature. J. Analyl. Appl. Pyrol., 79, 147-153.

[15] Encinar, J. M., Gonzalez, J. F., Martinez, G., Roman, S. (2009). Catalytic pyrolysis of exhausted olive oil waste. J. Analyl. Appl. Pyrol., 85, 197-203.

[16] Sushil, S., Batra, V. S. (2008). Catalytic applications of red mud, and aluminum industry waste: A review. Applied Catalysis B: Environmental, 81, 64-77.

[17] Ordonez S, Sastre H, Diez FV. Catalytic hydrodechlorination of tetrachloroethylene over red mud. J. Hazardous Materials, 2001; B81:103-114.

[18] Alvarez, J., Rosal, R., Sastre, H., Diez, F. V. Characterization and deactivation of sulfide red mud used as hydrogenation catalyst. Appl. Catal A: General, 1995; 128: 259-273.

[19] Alvarez, J., Ordonez, S., Rosal, R., Sastre, H., Diez, F. V. (1999). A new method for enhancing the performance of red mud as a hydrogenation catalyst. Applied Catalysis A: General, 180, 399-409.

[20] Cakici, A. I., Yanik, J., Ucar, S. (2004). Utilization of red mud as catalyst in conversion of waste oil and waste plastics to fuel. J. Mater Cycles Waste Manag., 6, 20-26.

[21] López, A., De Marco, I., Caballero, B. M., Laresgoiti, M. F., Adrados, A., Aranzabal, A. (2011). Catalytic pyrolysis of plastic wastes with two different types of catalysts: ZSM-5 zeolite and Red Mud. Applied Catalysis B: Environmental, 104, 211-219. 
[22] Klopries, B., Hodek, W., Bandermann, F. (1990). Catalytic hydroliquifaction of biomass with Redmud and $\mathrm{CoO}-\mathrm{MoO} 3$ catalyst. Fuel, 69,448-455.

[23] Karimi, E., Briens, C., Berruti, F., Moloodi, S., Tzanetakis, T., Thomson, M. J., Schlaf, M. (2010). Red Mud as a Catalyst for the Upgrading of Hemp-Seed Pyrolysis Bio-oil. Energy \& Fuels, 24, 6586-6600.

[24] Karimi, E., Gomez, A., Kycia, S. W., Schlaf, M. (2010). Thermal decomposition of acetic and formic acid catalyzed by red mud-implications for the potential use of red mud as a pyrolysis bio-oil upgrading catalyst. Energy \& Fuels, 24, $2747-2757$.

[25] Hamilton, R. J., Rossell, J. B., (1986). Analysis of oils and fats. Elsevier Applied Science, New York.

[26] Xu, S., Zou, L., Ling, X., Wei, Y., Zhang, S. (2014). Preparation and thermal reliability of methyl palmitate/methylstearate mixture as a novel composite phase change material. Energy and Buildings, 68, 372-375.

[27] Yan, Q., Liang, C., Zhang, L. (2008). Experimental study on the thermal storage performance and preparation of paraffin mixtures used in the phase change wall. Solar Energy Materials and Solar Cells, 92, 1626-1532.

[28] Yuan, Y., Zhang, N., Tao, W., Cao, X., He, Y. (2009). Fatty acids as phase change materials: a review. Renewable and Sustainable Energy Reviews, 13, 318-345.

[29] Zanzi, R., Sjostrom, K., Bjornbom, E. (2002). Rapid pyrolysis of agricultural residues at high temperature. Biomass \& Bioenergy, 23, 357-366.

[30] Vitolo. S., Petarca, L., Bresci, B. (1999). Treatment of olive industry wastes. Biores. Technol. 67, 129-137.

[31] Agblevor, F. A., Besler, S., Wiselogel, A. E. (1995). Fast pyrolysis of stored biomass feedstocks. Energy and Fuels, 9,635-638.

[32] Saiz-Jimenez, C., De Leeuw, J. W., Gomez-Alarcon, G. (1987). Sludge from waste water of the olive processing industry: A potential soil fertilizer. The Science of the Total Environment, 62,445-452.

[33] Sacchi, R., Addeo, F., Paolillo, L. (1997). ${ }^{1} \mathrm{H}$ and ${ }^{13} \mathrm{C}$ NMR of virgin olive oil: An overview. Magnetic Resonance in Chemistry, 35, S133-S145.

[34] Zakh, H. \& El Abbassi, A. (2012). Potential use of olive mill wastewater in the preparation of functional beverages: A review. J. Functional Foods, 4 (1), 53-65.

[35] Yathavan, B. K, Agblevor, F. A. (2013). Catalytic pyrolysis of pinyon-juniper wood using red mud and HZSM-5. Energy and Fuels, 27, 6858-6865.

[36] Agblevor, F. A., Besler-Guran, S. (2002). Fractional pyrolysis of biomass for high-valued products. Fuel Chemistry Preprints, 47 (1), 374-375.

[37] Agblevor, F. A., Beis, S., Mante, O., Abdoulmoumine, N., McClung, R. (2010b). Production of stable pyrolysis oils using fractional catalytic pyrolysis. Energy \& Fuels, 24, $4087-$ 4089 .
[38] Agblevor, F., Beis, S., Mante, O., Abdoulmoumine, N. (2010c) Fractional catalytic pyrolysis of hybrid poplar wood. Ind. Eng. Chem. Res., 49, 3533-3538.

[39] Mante, O., \& Agblevor, F. (2011). Catalytic conversion of biomass to bio-syncrude oil. Biomass Conversion and Biorefinery, 1 (4), 203-215.

[40] Hribernik, A., \& Kegl, B. (2007). Influence of biodiesel on the combustion and emission formation in direct injection (DI) diesel engine. Energy and Fuels, 21, 1760-1767.

[41] Groose, A. V., Morrell, J. C., Mattox, W. J. (1940). Catalytic cyclization of aliphatic hydrocarbons to aromatics, Industrial and Eng. Chemistry, 32 (4), 528-531.

[42] Greensfelder BS, Archibald RC. US Patent \#2337190, Cyclization of hydrocarbons. 1943.

[43] Alka, K., Lunsford, J. H. (1977) Surface reactions of oxygen ions. 1. Dehydration of alkanes by O- on MgO, J. Phys. Chem., 81 (14), 1393-1398.

[44] Herrington, E. F. G., Rideal, E. K. (2013). On the catalytic cyclization of aliphatic hydrocarbons. I., Proc. R. Soc. Lond, A 1945 184, doi:10.1098/rspa.1954.0027, published November 1945.

[45] Boocock, D. G. B., Konar, S. K., Mackay, A. (1992). Fuels and chemicals from sewage sludge 2. The production of alkanes and alkenes by the pyrolysis of triglycerides over activated alumina. Fuel, 71, 1291-1297.

[46] Pestman, R., van Duijne, A., Pieterse, J. A. Z., Ponec, V. (1995). The formation of ketones and aldehydes from carboxylic acids, structure-activity relationship for two competitive reactions, J. Molecular Catal. A: Chemical, 103, 175-180.

[47] Vonghia, E., Boocock, D. G. B., Konar, S. K., Leung, A. (1995). Pathways for the deoxygenation of triglycerides to aliphatic hydrocarbons over activated alumina. Energy and Fuels, 9, 1090-1096.

[48] Leung, A., Boocock, D. G. B., Konar, S. K. (1995). Pathways for the catalytic conversion of carboxylic acids to hydrocarbons over activated alumina. Energy \& Fuels, 9, 913920.

[49] Gaertner, C., Serrano-Ruiz, J. C.; Braden, D.; Dumesic, J. J. (2009). Catalytic coupling of carboxylic acids by ketonization as a processing step in biomass conversion. J. Catal., 266, 7178 .

[50] Deng, L., Fu, Y., Guo, Q. X. (2009). Upgraded acidic components of biooil through catalytic ketonic condensation. Energy \& Fuels, 23, 564-568.

[51] Peters, J., Zhang, X., Pham, T., Gangaharan, A., Zhu, X., Gallasso, R., Resasco, D., Mallinson, R. (2010). In Proceedings, AIChE 2010 Annual Meeting, 2010, Salt Lake City.

[52] Jozwiak, W. K., Kaczmarek, E., Maniecki, T. P., Ignaczak, W., Maniukiewicz, W. (2007) Reduction behavior of iron oxides in hydrogen and carbon monoxide atmospheres, Applied Catalysis A: General., 326, 17-27. 